

\title{
Lilia Luján: arte, derechos humanos y conciencia
}

\author{
Lilia Luján ${ }^{1}$ \\ Artista Independiente
}

México

Recibid@: 18 de octubre de 2019 Aprob@@: 22 de febrero de 2020

\begin{abstract}
Artista mexicana autodidacta, se inicia en las artes plásticas desde 1995. Ha explorado y experimentado con diversas técnicas, materiales y soportes de forma multidisciplinar, especializándose esencialmente en pintura, escultura alternativa, murales y la docencia con niños, adolescentes y adultos con desigualdad de condiciones sociales. Cuenta con veinticinco murales dirigidos y ha realizado más de cuatrocientas exposiciones nacionales e internacionales. Correo electrónico: lilialujan@hotmail.com
\end{abstract}




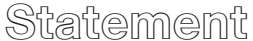

En los últimos años, preocupada por el acontecer diario y con el propósito de ayudar a crear conciencia, empiezo la creación de las series temáticas digital art: Conciencia, Migrantes Universales, Sin Barreras y El Decir de la Luz. Estas tratan sobre temas de alta relevancia y ocupación a nivel mundial, como derechos humanos, cambio climático, cultura de la paz, migración, equidad de género, inclusión y diversidad.

A lo largo del tiempo se ha constatado que el arte, más allá del goce de la belleza y de la estética, también nos ayuda a reflexionar a través de códigos visuales; el mensaje se hace claro y directo, accesible para todos, pues el arte es finalmente un lenguaje universal. Nosotros los artistas tenemos el deber y el compromiso de utilizar esta valiosa herramienta para generar un cambio, sacudir conciencias, enviar una provocación positiva y, a la vez, proactiva. Mi obra, inspirada en dichos temas, pretende mover las fibras del observador, conectarlo nuevamente con los aspectos simples y esenciales del ser. Asimismo, busca reivindicar los derechos humanos universales, retomar el diálogo con la naturaleza e inspirar hacia la revalorización de nuestro entorno, el cuido del planeta y el desecho de lo efímero, lo material. Esta iniciativa propone, también, enfocarnos más en un plano de crecimiento espiritual, retomar el camino hacia una hermandad libre de prejuicios y etiquetas sociales, donde se pueda disfrutar de la convivencia armónica, en paz. 
Mi trabajo artístico es básicamente un ejercicio catártico, donde intento conjugar todos los elementos en armonía y equilibrio. La intuición, la experimentación y la estética son la base de mi técnica. La raíz de mi visión plástica, mi propia esencia, mis sentidos...

Lilia Luján

ESCENA. Revista de las artes, 2020, Vol. 80, Núm. 1, pp. ISSN 2215-4906 


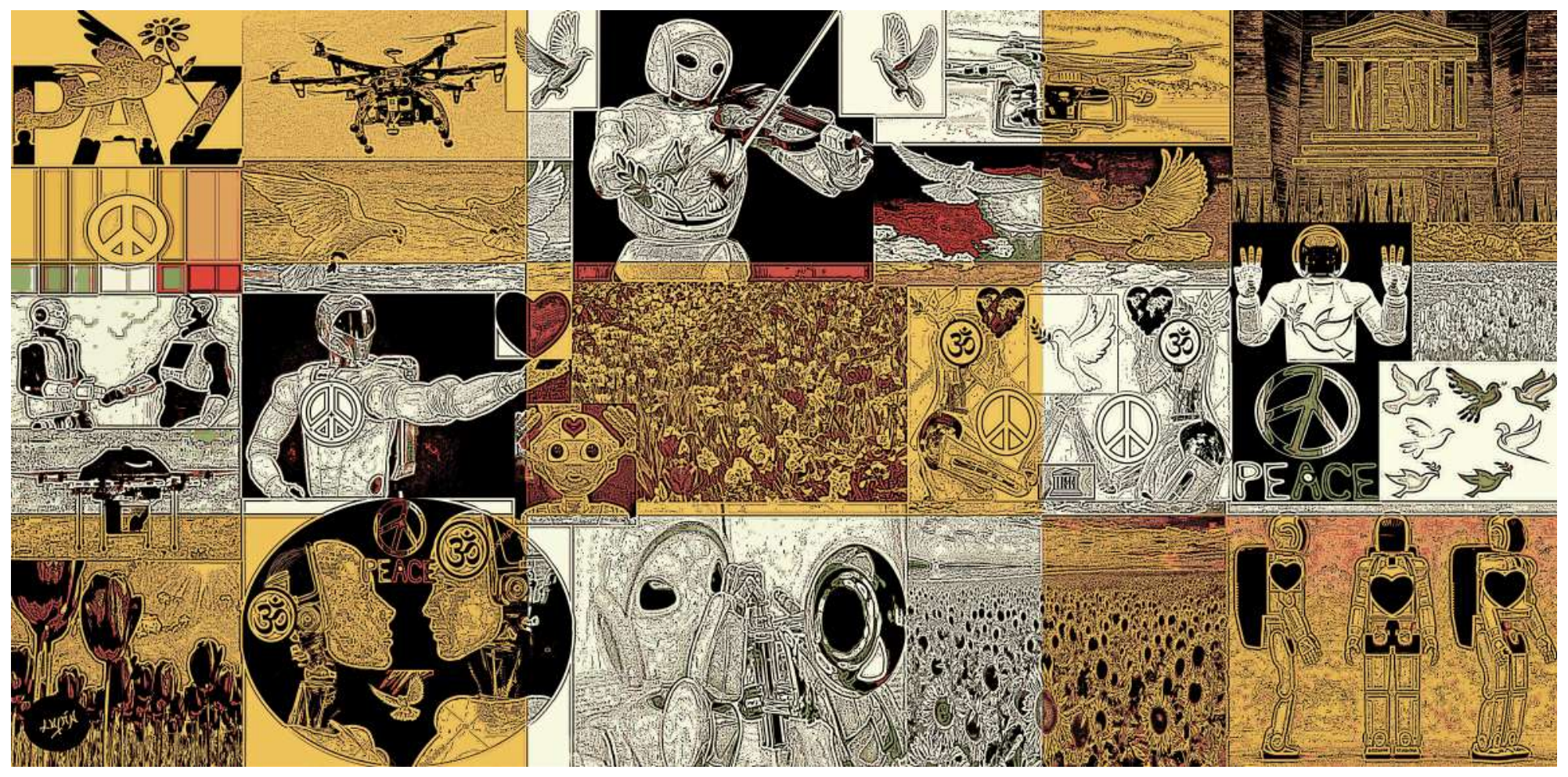

Harmony. (2018). Mixta digital / Canvas, 60x120cm Obra seleccionada International Day of Peace 2018, UNESCO, París, Francia. 

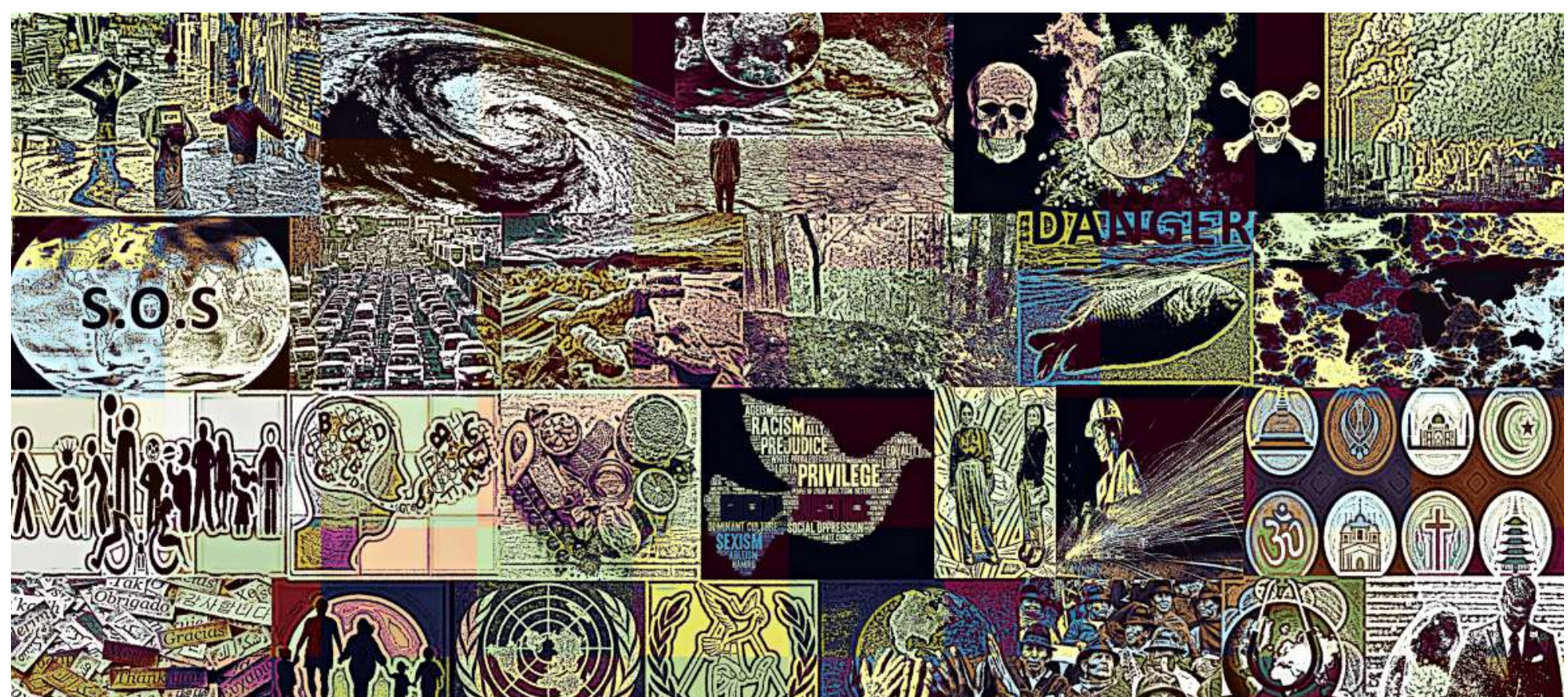

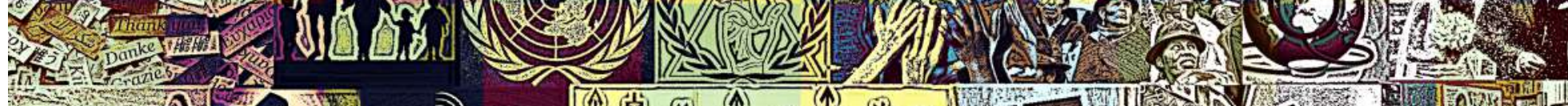

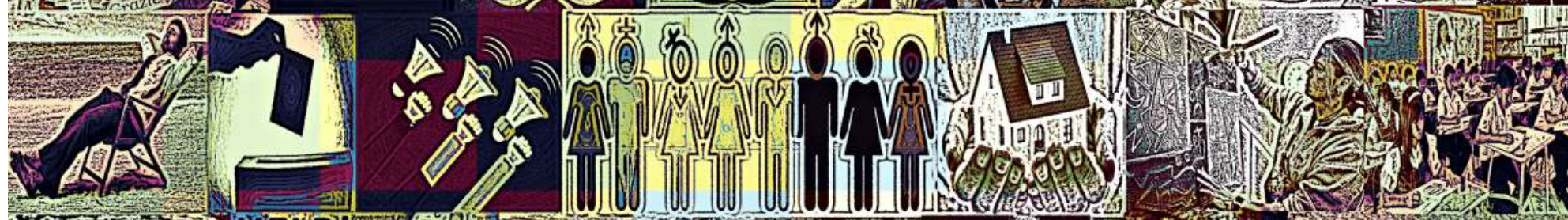

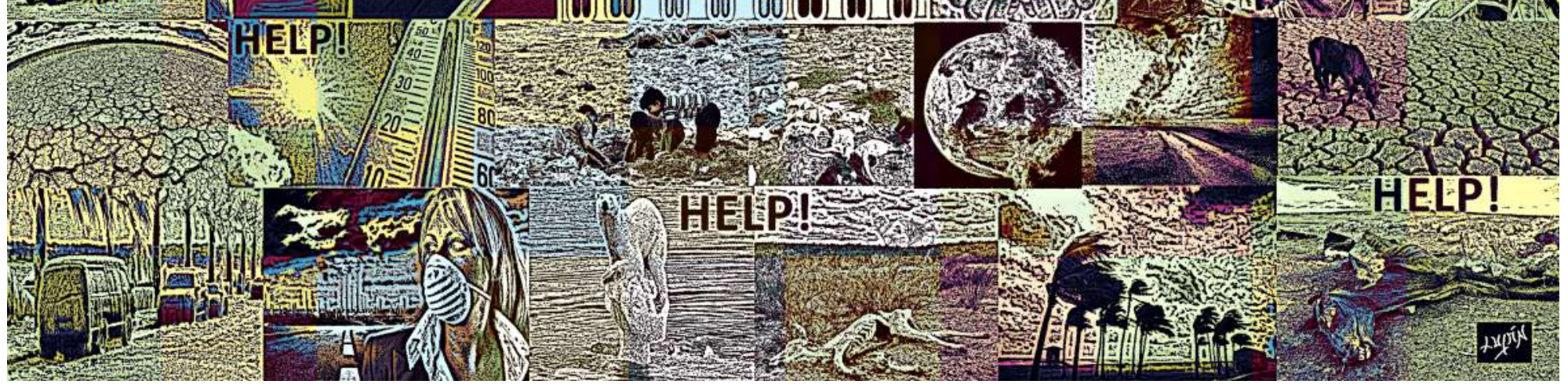




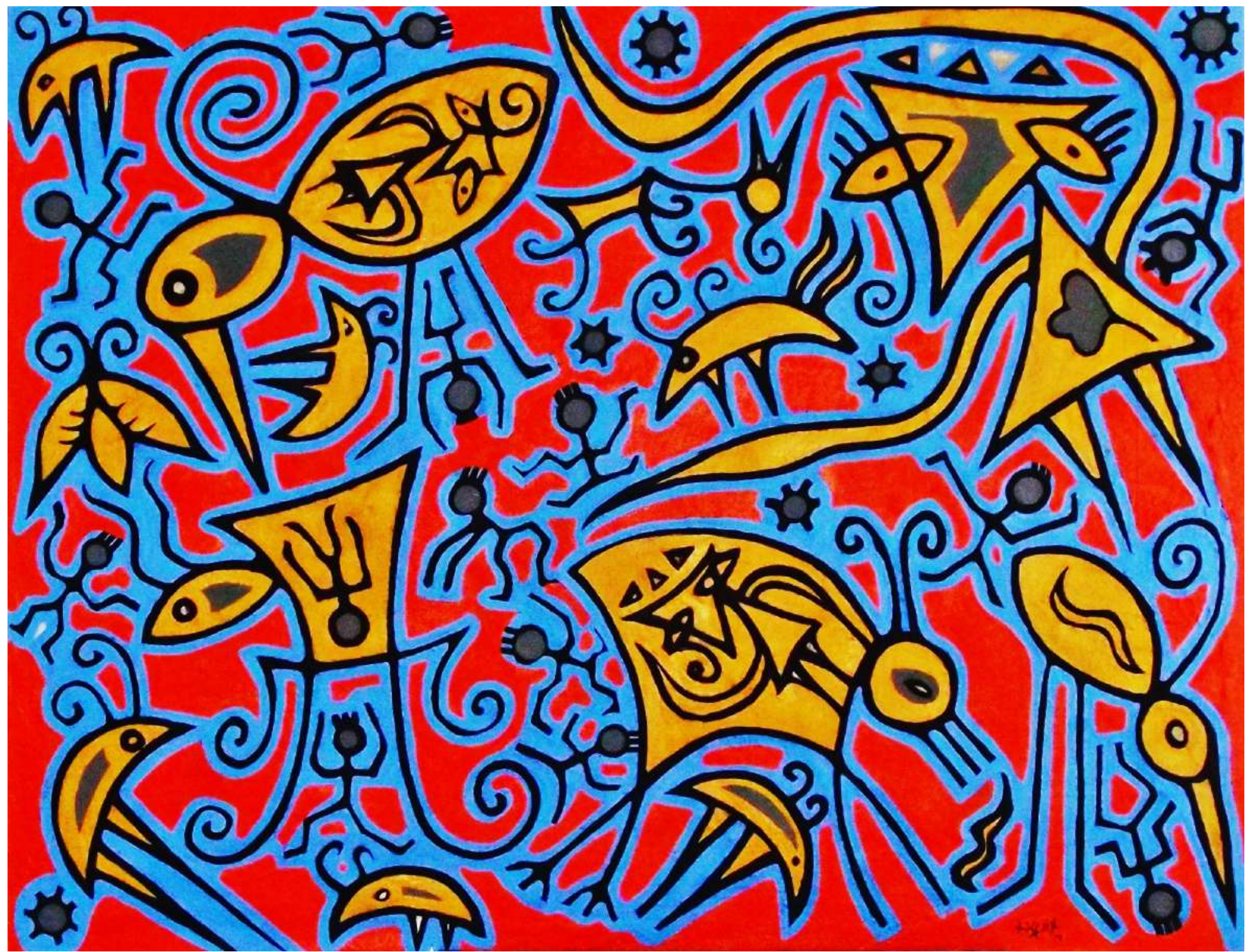

Wake up. (2014). Mixta / Canvas, 100x130cm. Obra seleccionada en la 6th Beijing Intenational Art Biennalememory and Dream, National Art Museum of China.

ESCENA. Revista de las artes, 2020, Vol. 80, Núm. 1, pp. ISSN 2215-4906 


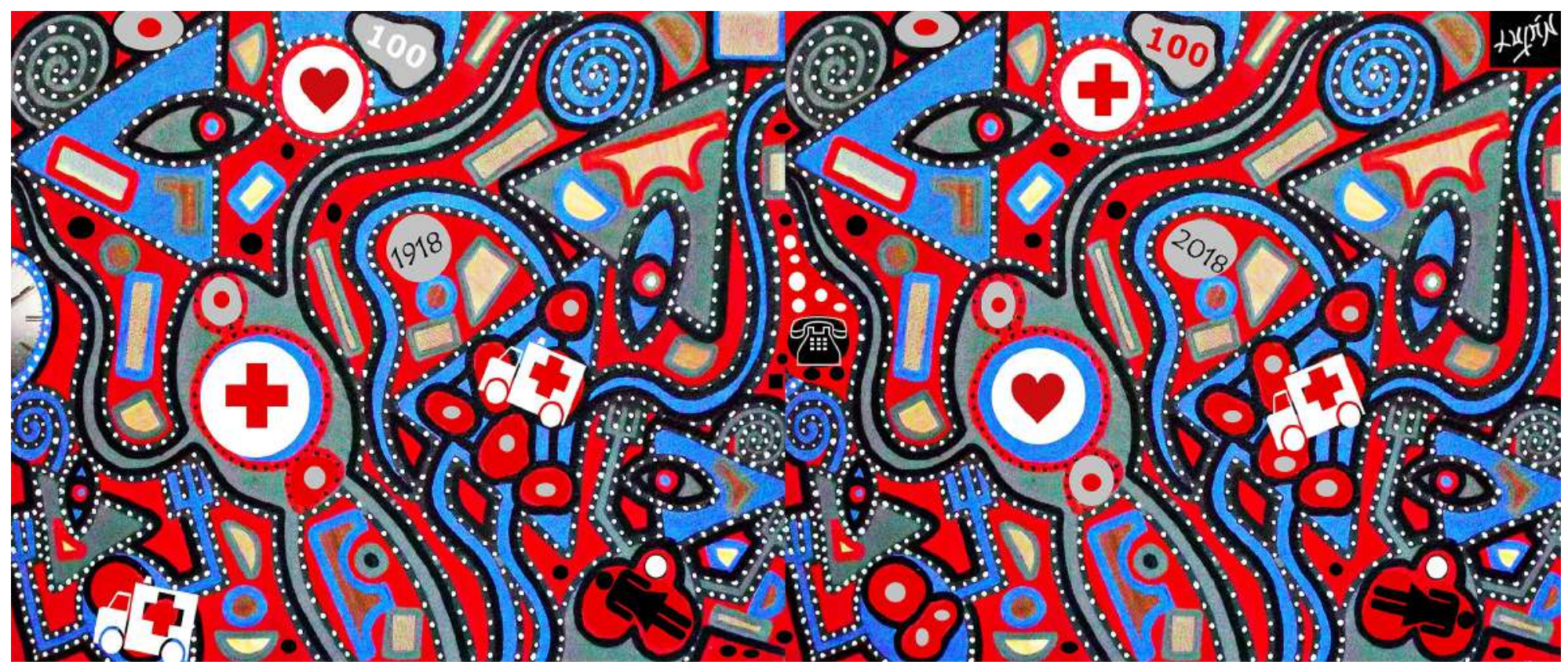

Informalismo II. (2018). Mixta / Tela, 100x200cm. Obra conmemorativa Aniversario Centenario Cruz Roja Mexicana. 